\title{
Is Gun Control Likely To Reduce Violent Killings?
}

\author{
Frank Zimring
}

One of the major arguments for the elimination of firearms, and derivatively for gun control laws, is that such measures would reduce the number of criminal homicides. ${ }^{1}$ It has been argued, however, that eliminating guns would have no such effect because if somebody wants to kill, he will find a weapon to achieve "his destructive goal"; there is, it is said, more than one way to skin a cat. ${ }^{2}$ This paper is an attempt to bring this phase of the gun control debate closer to a resolution, through analysis of data from the Police Department of the City of Chicago on reported criminal homicides and serious, but not fatal, criminal assaults during 1965, 1966, and 1967.

\section{Homicide and THE InTENTION To KiLL}

If all homicides resulted from such a single-minded intention to kill as gangland killings, laws prohibiting firearms would not have a substan-

Frank Zimring is Assistant Professor of Law, The University of Chicago, and Research Associate, Center for Studies in Criminal Justice. This study was supported by the Center for Studies in Criminal Justice at the University of Chicago. The study would not have been possible without the cooperation of the Homicide-Sex Division of the Chicago Police Department, and particularly Commander Francis Flanagan and Detective P. D. Conway. The author wishes to thank Professor Hans Zeisel, of the University of Chicago Law School, for his monumental assistance in the preparation of this note, and Fred Axley, a second-year student at the University of Chicago Law School, for his diligent research assistance.

1 "It would be fairly easy to reduce the number of murders. Rational and effective laws would cut homicide sharply." Norval Morris, quoted in Look, Sept. 19, 1967, at 32.

2 "More than the availability of a shooting weapon is involved in homicide. Pistols and revolvers are not difficult to purchase ... in Philadelphia. . . The type of weapon used appears to be, in part, the culmination of assault intentions or events and is only superficially related to causality. To measure quantitatively the effect of the presence of firearms on the homicide rate would require knowing the number and type of homicides that would not have occurred had not the offender-or, in some cases, the victimpossessed a gun. Research would require determination of the number of shootings that would have been stabbings, beatings, or some other method of inflicting death had no gun been available. It is the contention of this observer that few homicides due to shootings could be avoided merely if a firearm were not immediately present, and that the offender would select some other weapon to achieve the same destructive goal. Probably only in those cases where a felon kills a police officer, or vice versa, would homicide be avoided in the absence of a firearm." $M$. Wolfgang, Patterns in Criminal Homicine 82-83 (1958). 
tial effect on homicide. Even assuming such assassins would be unable to obtain guns-a doubtful supposition-they would resort to other weapons on the order of dynamite to achieve their intention. But not all homicides are so unambiguously motivated. The question is: Do a significant proportion of homicides result from a less deliberate and determined intention? If this question may be answered in the affirmative, and if the probable substitute for firearms in these situations is less likely to lead to death, then the elimination of guns would reduce the number of homicides.

The hypothesis is more easily stated than proved. For obvious reasons, there are no precise data on the intention of an attacker toward his victim-whether he wished to wound or injure, with some apprehension of the risk of death or some desire to kill, or whether he single-mindedly intended to kill at any cost. Either of these mental states would be consistent with a finding of murder if homicide results. But the more ambiguous intention might well lead to the termination of an attack before lethal consequences ensue. The barroom fight ends when one of the two participants has been stabbed, shot, or beaten into submission. ${ }^{3}$ At that point the issue has been decided. Similarly, the violent domestic dispute may end decisively without fatal consequences.

A series of statistics for the city of Chicago throws light on the degree to which homicides result from an ambiguous, rather than a singleminded, intention to kill. The first table corncerns the relationship between attacker and victim in homicide cases:

TABLE 1

Relationship Between Homicide Victim and Attacker: Chicago, 1967

\begin{tabular}{lc}
\hline \multicolumn{1}{c}{ Relationship } & $\%$ \\
\hline Friends and acquaintances & 41 \\
Spouse or lover & 20 \\
Other family & 7 \\
Neighbors & 3 \\
Business & 3 \\
No relationship & 22 \\
Undetermined & 4 \\
Total & 100 \\
Number of cases & 554 \\
\hline
\end{tabular}

More than two-thirds of all killings involved spouses, lovers, friends, or tavern guests as victim and attacker.

Glosely related to data on relationship are statistics about the motive of the attack:

3 For statistics on non-fatal serious assaults, see Tables 7, 8, and 9 infra. See also WolfGang, supra note 2 , at 86 , for a discussion of the quality of intention in homicides by beating in Philadelphia. 
TABLE 2

Motives of Homicide as Established by Police: Chicaco, 1967

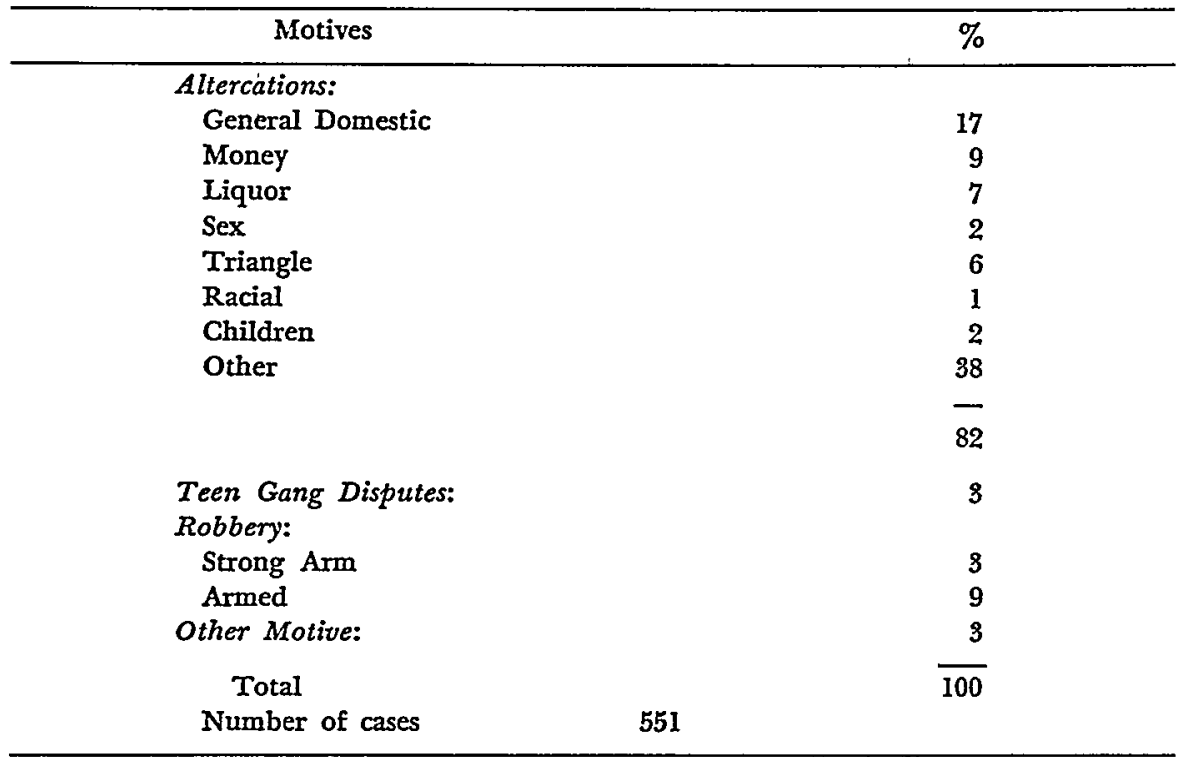

$82 \%$ of the homicides in Chicago in 1967 occurred as a result of altercations-domestic, money, liquor, etc.-precisely the situations where the intention is more apt to be ambiguous rather than single-minded.

Third, a comparison of victims of homicide with victims of serious assaults, with respect to their race and sex, shows:

Victims of homicides and victims of serious assaults are distributed quite similarly by race and sex among the population and differ substantially in these characteristics from the Chicago population as a whole. (See Table 3.)

Next, it should be noted that only $30 \%$ of the victims of fatal gunshot attacks in 1967 were wounded by more than one shot. While data are not available on the number of shots fired, it may be readily assumed that the majority of the $70 \%$ of single wound homicides occurred in situations where the attacker did not exhaust the multiple shot capacity of his firearm."

Finally, in 54\% of the situations which led to homicide in 1967, the police noted that the offender or the victim or both had been drinking prior to the homicidal attack. This figure probably does not include a number of situations in which the police officer was unable to determine whether intoxicants were involved.

4 When one offender kills more than one victim, this inference may not hold. Nine cases where the police noted the weapon was exhausted were found in the 1967 records. More may have gone without notation. 
TABLE 3

Homicioe and Serrous Assault Victims and Chicago Population by Race and Sex

\begin{tabular}{cccc}
\hline & $\begin{array}{c}\text { Homicide } \\
\text { Victims } \\
1967\end{array}$ & $\begin{array}{c}\text { Serious Assault } \\
\text { Victims of Gun } \\
\text { and Knife Attacks } \\
\text { 5th Period, }\end{array}$ & $\begin{array}{c}\text { Chicago } \\
\text { Population } \\
19601\end{array}$ \\
\hline $\begin{array}{c}\text { White } \\
\text { Male }\end{array}$ & 15 & 15 & $\%$ \\
Female & 7 & 4 & 37 \\
Negro & 59 & & 39 \\
Male & 12 & 61 & 11 \\
Female & & 15 & 12 \\
Other & 6 & & -2 \\
Male & 1 & 5 & -2 \\
Female & $100 \%$ & 1 & $100 \%$ \\
Total & 553 & 480 & $3,540,100$ \\
Number & & $100 \%$ & 1 \\
\hline
\end{tabular}

1 More recent data on Chicago population by both race and sex are not available. Nonwhites are estimated to have comprised $30 \%$ of the city's population in April 1968, as compared with $24 \%$ in 1960 . Hospital Planning Council for Metropolitan Chicago, Chicago Regional Hospital Study: Population Estimates for Municipalities and Counties in the Chicago Consolidated Area, 1967 and 1968, Table 2 (mimeo. July 1968).

2 Less than $0.5 \%$.

It may be inferred from these data that many homicides are related to variable states of intention and that a significant proportion do not result from an attack committed with the single-minded intention to kill. The next question that must be asked in order to determine whether elimination of firearms would result in a lower homicide rate, is whether firearms as a class are more dangerous in the normal assault situation than the most dangerous probable substitute weapon. If they are not, then their elimination would not reduce the homicide rate, which is a function of the dangerousness of the weapons used multiplied by the number of serious attacks. Before an answer may be sought from the data, it is necessary to define "dangerousness" of a weapon in a manner that permits empirical study.

\section{Defining Dangerousness}

To say that weapon $\mathrm{A}$ is more dangerous than weapon $\mathrm{B}$ might mean either that weapon A can facilitate the implementation of intentions to attack in situations where weapon B cannot, or that consummated attacks with weapon $A$ are more dangerous than consummated attacks with weapon B, or both. Certainly, the capacity of a particular weapon 
to make a homicidal attack possible-its range-is an element of any definition of weapon dangerousness. ${ }^{5}$ But no available experience statistics indicate how many attacks with weapon $A$ would not have been attacks at all if weapon $B$ and not weapon $A$ were available.

We do know (1) that firearms as a class have a greater range for carrying intention into act than any other frequently used assault mechanism, and (2) that most homicides involve individuals who are acquainted with one another and take place in "inside" locations such as homes, taverns,

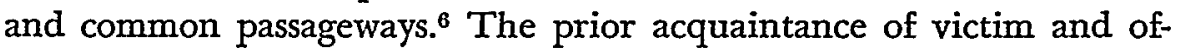
fender and the location of most homicidal attacks suggest that it is correct to assume that weapon range is a critical factor in attack situations in only a comparatively small number of cases. ${ }^{7}$ Nonetheless, to the limited extent that range has any bearing on the dangerousness of weapons in attack, guns must be considered more dangerous than alternative weapons in common usage. Where range is important, as in the killing of police, the absence of firearms may have preventive effects beyond the scope of this study.

\section{The Most Dangerous Probable Substitute Weapon}

In order to assess the impact of effective gun control on homicide fairly, the dangerousness of firearms in attack situations should be judged against the dangerousness of the most dangerous weapon which probably would be-as opposed to could be-used in assault situations were firearms not available.

There are a number of dangerous instrumentalities widely available to most of the population. Knives, other cutting instruments, automobiles, and blunt instruments of all kinds are freely available. Hands and feet, potentially lethal instruments in their own right, are a part of man's standard equipment. Some, but not all, poisons are available in various forms. Many flammable and explosive substances are within the average citizen's reach. Thus, weapon availability is a threshold which excludes only a few of the more exotic or technically sophisticated means of destruction. A far more important screening question is whether a particular form of attack instrumentality is available in the perceptual sense-likely to enter the thoughts and physical reach of an individual who is contemplating attack.

5 Range is of particular importance in political killings and in killing armed individuals. Thus, factors affecting range would concededly affect the rate of police officers killed. See Wolfgang, supra note 2 , at 83.

6 In 1967, over 2/3 of Chicago homicides took place in inside locations. See also HomIcide Section, Aggrayated Assault Section, Review Unit, Chicago police Dep't., Murder ANALYsis-1966. For statistics on relationship, see Table I supra.

7 See Wolfgang, supra note 2 , at 83. 
A rough estimate of the perceived availability of instrumentalities as murder weapons can be obtained by analyzing the type of weapons actually used in homicides reported to the police:

Homicide by Weapon: Chicago, 19668

\begin{tabular}{lr}
\hline & $\%$ \\
\hline Firearms & 52 \\
Knives & 30 \\
Other weapons & 8 \\
No weapon & 10 \\
Not known & 1 \\
& $100 \%$
\end{tabular}

It is true, of course, that some attack instruments may be underreported because it is difficult to discover that they have caused a death (e.g., some forms of poison) or because death caused by the instrumentality is not normally suspected as intentionally caused whether or not intention was actually present (e.g., automobiles). Poison is not even listed as a cause of death in Chicago homicide in 1966. An automobile is listed as accounting for one suspected intentional death. The great disproportion between knife and bodily attacks and other instrumentalities does not allow for the serious competition of automobiles and poison.

Thus, unless the people who make homicidal attacks with firearms are radically different from those who make homicidal attacks with other weapons known to the police, the absence of guns would produce a great many more knife attacks and a substantially greater number of attacks using hands or feet as potentially homicidal weapons.

There are two separate kinds of evidence suggesting that guns and knives are used by the same sorts of people:

As table 4 shows, in general, the same kinds of altercations produce gun and knife killings.

As table 5 shows, firearms and knives are used by whites and $\mathrm{Ne}$ groes in about the same proportions.

Although knives result in three times as many homicides as attacks with the hands or feet, it is not necessarily true that knife attacks are more physically dangerous than all kinds of attacks with hands or feet. Some forms of attack involving the hands or feet, such as strangulation, might conceivably result in death in a greater proportion of attacks in earnest than some forms of knife attack. But comparison of the propor-

8 MUrder ANalysis-1966, supra note 6. 1967 homicides by weapon show the same pattern: guns $57 \%$, knives $25 \%$, hands or feet $10 \%$, other $8 \%$, total number 553 . 
TABLE 4

Police-Nominated Motive of Homicides by Weapon: Chicago, 1966

\begin{tabular}{|c|c|c|c|}
\hline & $\begin{array}{c}\% \\
\text { Shot }\end{array}$ & $\begin{array}{c}\% \\
\text { Stabbed }\end{array}$ & $\begin{array}{c}\% \\
\text { Other }\end{array}$ \\
\hline \multicolumn{4}{|l|}{ Altercations: } \\
\hline General Domestic & 21 & 25 & 23 \\
\hline Money & 6 & 7 & 2 \\
\hline Liquor & 2 & 8 & 4 \\
\hline Sex & 1 & 3 & 2 \\
\hline Gambling & 2 & 1 & 0 \\
\hline Triangle & 5 & $\mathbf{5}$ & 3 \\
\hline Theft (alleged) & - & - & 2 \\
\hline Children & 2 & 1 & 1 \\
\hline \multirow[t]{3}{*}{ Other } & 41 & 30 & 28 \\
\hline & - & - & - \\
\hline & 80 & 80 & 65 \\
\hline \multicolumn{4}{|l|}{ Robbery: } \\
\hline Strong Arm & - & - & 10 \\
\hline Armed & 9 & 9 & 4 \\
\hline Burglary: & 一 & 一 & - \\
\hline \multicolumn{4}{|l|}{ Sex: } \\
\hline Perversion & 2 & 3 & 5 \\
\hline Assault of Woman & - & 4 & 7 \\
\hline Wanton Use of Weapons: & 2 & - & 1 \\
\hline Undetermined: & 6 & 4 & 4 \\
\hline \multicolumn{4}{|l|}{ Gangland Type: } \\
\hline Organized & 1 & - & - \\
\hline \multicolumn{4}{|l|}{ Crim. of Victim } \\
\hline Burglar & - & - & - \\
\hline Undetermined & 一 & - & 1 \\
\hline \multicolumn{4}{|l|}{ other: } \\
\hline Mercy Killing & - & - & 1 \\
\hline \multirow[t]{2}{*}{ Mental Disorder } & - & - & 2 \\
\hline & $100 \%$ & $100 \%$ & $100 \%$ \\
\hline Number & 265 & 152 & $93^{\circ}$ \\
\hline
\end{tabular}

TABLE 5

Homicide WeApon Used by RACB aNd SEX OF OfFender: Chicago, 1967

\begin{tabular}{|c|c|c|c|c|}
\hline & \multicolumn{2}{|c|}{ Male } & \multicolumn{2}{|c|}{ Female } \\
\hline & Negro & White & Negro & White \\
\hline Guns & 60 & 59 & 40 & 50 \\
\hline Knives & 21 & 16 & 54 & 33 \\
\hline No weapon & 12 & 17 & 1 & 0 \\
\hline Other & 8 & 8 & 4 & 17 \\
\hline Total & $100 \%$ & $100 \%$ & $100 \%$ & $100 \%$ \\
\hline $\begin{array}{l}\text { Number of } \\
\text { Offenders }\end{array}$ & 880 & 71 & 72 & 12 \\
\hline
\end{tabular}


tions of killings does indicate one of two things: (1) if attacks using the hands or feet are very much more common than the homicide statistics indicate, they are physically very much less dangerous than knife attacks, or (2) if attacks using the hands or feet are physically more dangerous than knife attacks, they are very much less used and therefore less available in the perceptual sense.

Strangulation is very rare in Chicago. There were six such reported fatalities in 1966: most homicides by hand or foot attack were attributable to beatings. Since beatings are common in attack situations, it is more probable that knives are physically more dangerous. In either case, since we are talking about the predominant probable substitute for gun attacks, the balance would seem to favor the use of knife attacks. The use of beatings would lead to even stronger differences than those noted.

\section{Fatality Rates from Gun and KnIfe Attacks}

Chicago police records include data which permit useful comparison between serious knife and gun attacks and between knife and gun killings. (See Table 6.) For 1967, these data show:

2.3 times as many serious knife attacks were reported to the police as gun attacks.

Knives accounted for less than half the number of homicides that guns did.

The rate of knife deaths per 100 reported knife attacks was less than $1 / 5$ the rate of gun deaths per 100 reported gun attacks.

These figures support the inference that if knives were substituted for guns, the homicide rate would drop significantly.

TABLE 6

Number of Non-Fatal Attacks and Homicmes With Knives and Firearms Recorded by POLICE: ChicAGo, 1965-67

\begin{tabular}{lcc}
\hline & $\begin{array}{c}\text { Non-Fatal } \\
\text { Attacks }\end{array}$ & Homicides \\
\hline 1965 & & \\
Knives & 5,285 & 104 \\
Firearms & 1,298 & 195 \\
1966 & & \\
Knives & 5,230 & 152 \\
Firearms & 1,873 & 265 \\
1967 & & \\
Knives & 5,612 & 185 \\
Firearms & 2,412 & 317 \\
Total & & \\
Knives & 16,127 & 391 \\
Firearms & 5,583 & 777 \\
\hline
\end{tabular}


The figures, though not the inference, are subject to qualification, however. Not all gun or knife attacks are called to the attention of the police. That attacks reported to the police are not a complete census of weapon attacks in the population would not, by itself, disturb the validity of inferences made from comparisons of police statistics. But if a plausible argument can be made that the police statistics are not a reliable index of attack rates in the total population, and if the factors which undermine the use of police statistics as an index could be expected to overstate the proportion of knife relative to gun attacks reported, the validity of inferences from police attack statistics could be questioned.

Two plausible reasons why attacks with one weapon could be more often reported than attacks using a second weapon may be noted. First, the more serious a victim perceives an attack to be, the more likely it is that he will report the attack to the police. Attacks with weapons which are considered more serious will be reported to the police proportionately more often than weapons considered less serious. It must be stated that we do not here deal with the fine distinctions that people may make regarding the lethal potential of various weapons. Thus, if individuals considered both knife and gun attacks to be very serious, the marginal differences in their opinions regarding the two weapons could not be expected to produce significant reporting differentials. Second, to the extent that aggressive patrol, investigation, police pressure on victims to promote disclosure, or a patrolman's decision to report an attack may affect police records, the police perception of weapon dangerousness will influence the proportional relationships found in police statistics. A series of interviews of Chicago police officials at various levels indicates that the unanimous feeling of concerned police officers is that gunshot attacks are more dangerous than knife attacks. To the extent that police and victim perceptions distort police statistics, therefore, they apparently result in underestimation rather than overestimation of the ratio of knife attacks to gun attacks in Chicago.

To rebut the inference that substituting knife attacks for gun attacks would reduce the homicide rate, it can also be argued that because a knife is viewed as a less serious weapon than a gun, a lower proportion of knife attacks represent attacks in earnest. The statistics clarify the form such an argument would have to take. First, it can be noted that the use of attacks reported to the police as a standard to construct attack proportions has already screened out a certain number of attacks which are not considered terribly serious, because it is plausible that attacks perceived of as being more serious are more often reported. Second, in order to equalize the number of deaths per 100 attacks in earnest with each weapon, the "non-earnest knife attack" hypothesis must explain 
over $75 \%$ of the total number of reported knife assaults even if it is assumed that every firearm attack reported to the police in 1966 represents an attack in earnest. To the extent that less than all firearm attacks are considered in earnest, an even greater proportion of knife attacks must be discounted. On its face, this seems implausible. The demographic similarity between knife attack victims and homicide victims is an additional indication that the two statistics may be two products of closely similar forms of attack, in essence a continuum rather than two discrete behaviors. Given the magnitude of the difference between reported knife and gun assaults, and the substantial probability that reporting biases underestimate the proportional impact of knife assaults if they have any influence at all, the non-earnest hypothesis seems an incomplete explanation of the different assault/killing ratios noted in Ghicago.

\section{The AtTack Study}

To obtain a more accurate impression of the character of knife and firearm attacks reflected in Chicago police records, police assault records for the period November 9-December 6, 1967 were analyzed in detail. The ratio of knife attacks to gun attacks was somewhat lower during this period than in any of the larger periods which have been the basic focus of analysis. Still, the number of knife attacks was substantially greater than the number of firearm attacks. And the ratio of gun killings to knife killings rose even more dramatically in this period than the ratio of gun attacks to knife attacks. There were 34 deaths attributable to firearms during this police period and eight deaths attributable to stabbings. The rate of knife deaths per 100 reported knife assaults was less than one-sixth of the rate of gun deaths per 100 reported gun assaults during this police period. This relationship is consistent with the overall one to five statistic found in the earlier large period comparisons.

One way of estimating the seriousness of an attack is to determine where the attacker sought to wound his victim. It may be assumed that actual wound location is a generally reliable indicator of the intended target, particularly for knives. It is highly unlikely that a great number of individuals intending superficial wounds to a non-vital area of the victim's body would by mistake stab him in the back, chest, neck or abdomen. Indeed, to the extent that "mistakes" produce a patterned difference between intended and actual location of wounds, the bias would probably understate rather than overstate the seriousness of a large group of attacks.

Table 7 sets forth the most serious area of the body where a wound was sustained in a knife or gun attack. It shows: 
70 knife wounds per 100 knife attacks occurred in areas that are associated with serious attacks-chest, abdomen, head and face, back, and neck-while only 56 gunshot wounds per 100 firearm attacks occurred in these areas.

Knife attacks resulting in wounds to non-vital areas-thighs and extremities-occurred no more frequently per 100 attacks than similar gun wounds. A smaller number of knife wounds to legs and thighs per 100 attacks is balanced against a larger number of knife wounds to arms, hands, and wrists per 100 attacks. Of every 100 reported firearm attacks, 12 resulted in no wound, while there was only one reported knife attack during the period which resulted in no wound.

TABLE 7

Non-Fatal and fatal Knife and Gun AtTacks by Location of Most Serious Wound: Chrcago, November 9-December 6, 1967

\begin{tabular}{|c|c|c|c|c|c|c|}
\hline \multirow{2}{*}{$\begin{array}{l}\text { Location } \\
\text { of most } \\
\text { serious } \\
\text { wound }\end{array}$} & \multicolumn{2}{|c|}{$\begin{array}{l}\text { Non-Fatal } \\
\text { Attacks }\end{array}$} & \multicolumn{2}{|c|}{$\begin{array}{c}\text { Fatal } \\
\text { Attacks }\end{array}$} & \multicolumn{2}{|c|}{ Total } \\
\hline & $\begin{array}{c}\text { Knife } \\
\%\end{array}$ & $\begin{array}{l}\text { Gun } \\
\%\end{array}$ & $\begin{array}{c}\text { Knife } \\
\%\end{array}$ & $\begin{array}{c}\text { Gun } \\
\%\end{array}$ & $\begin{array}{c}\text { Knife } \\
\%\end{array}$ & $\begin{array}{c}\text { Gun } \\
\%\end{array}$ \\
\hline \multicolumn{7}{|l|}{ Serious } \\
\hline Chest & 15 & 13 & 50 & 44 & 15 & 17 \\
\hline Abdomen & 17 & 12 & - & 18 & 17 & 13 \\
\hline Head & 15 & 11 & 38 & 32 & 16 & 14 \\
\hline Back & 10 & 3 & 13 & 3 & 10 & 3 \\
\hline Neck & 4 & 1 & - & - & 4 & 1 \\
\hline Shoulders & 8 & 8 & - & 3 & 8 & 7 \\
\hline Total & 69 & 48 & 100 & 100 & 70 & 56 \\
\hline \multicolumn{7}{|l|}{ Non-Serious } \\
\hline Legs & 7 & 28 & 一 & - & 7 & 24 \\
\hline Arms & 24 & 10 & - & - & 23 & 9 \\
\hline Missed & - & 14 & - & 一 & - & 12 \\
\hline Total & 31 & 52 & 一 & 一 & 30 & 45 \\
\hline Total & $100 \%$ & $100 \%$ & $100 \%$ & $100 \%$ & $100 \%$ & $100 \%$ \\
\hline Number & 358 & 213 & 8 & 34 & 366 & 247 \\
\hline
\end{tabular}

These data appear to support three inferences, each of which will be discussed in turn.

1. Not all gun attacks can be per se considered attacks in earnest. About $56 \%$ of the reported firearm attacks, including all of the fatal attacks noted during the sample police period, produced wounds in the chest, abdomen, head area, and the back and shoulders. It is, of course, true that many of the gun wounds in locations like the back or chest were not the kinds of wounds which led to fatalities. However, since we are using wound location as an index of the intended seriousness of an 
attack, and wound seriousness is an indication of outcome rather than intention, it is probably safe to assume that a substantial proportion of those gun attacks with dangerous area wounds could qualify as attacks in earnest, since they generated the risk of fatal consequences.

It can be argued, however, that since the relationship between the intended locale of an attack and the actual locale of the wounding is not complete, many of the firearm attacks that have been coded as misses, or attacks culminating in a wound no more serious than an arm, hand, hip, leg, or foot wound, were actually much more seriously intended. A proponent of this position would point out that when a police report indicates that a man firing a gunshot has missed, as it does in a substantial number of cases, there is no information on what area of the body the gunshot wound has missed, and therefore no inference may be drawn about the seriousness of the attack. The normal attack capacity of a firearm, however, is substantially more than one shot. If an individual does not wound a victim as seriously as he intended on the first try, he may try again. Since Table 7 only codes wounds by location of the most serious wound area of a particular attack, attacks coded in less serious areas are attacks in which the assailant did not try again, or at least had no greater success. If attacks resulting in multiple wounds are presumptively considered serious and added to those resulting in actual wounds to serious areas, the total is less than $58 \%$ of all gun attacks. (See Table 8.) Adding shotgun attacks not already included still leaves the total at roughly $60 \%$. It is doubtful, therefore, that all gun attacks are accompanied by even ambiguous intentions to kill.

2. A substantial proportion of the knife attacks reported to police appear to be attacks in earnest. The data show that a far greater number of knife attacks resulted in wounds to serious than to non-serious locations. If the 29 multiple knife wounds in non-serious locations are added to the knife wounds in serious areas, the total is approximately $77 \%$. (See Table 8.) While it is doubtless true that not all attacks resulting in serious area wounds were in earnest, it may also be presumed that some of the attacks resulting in non-serious wounds to the arms represent attacks in earnest partially thwarted by the victim's defensive use of his arms. In any event, it is difficult to argue that only an insignificant proportion of knife attacks are made in earnest.

3. There is no evidence that attacks in earnest are much more common with guns than with knives. Adding multiple wounds in non-serious locations to all serious wound locations makes possible a very rough estimate of the proportion of attacks which are in earnest for guns and knives. As indicated above, these figures are approximately $60 \%$ and $77 \%$, respectively. Obviously, these are only rough estimates. Their 


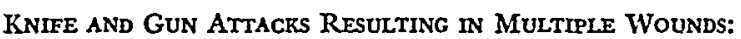

Chrasco, November 9-December 6, 1967

\begin{tabular}{lcc}
\hline & Knife & Gun 1 \\
\hline $\begin{array}{l}\text { Serious Area } \\
\text { Number of Multiple Wound Attacks } \\
\text { \% of- }\end{array}$ & 117 & 19 \\
$\quad \begin{array}{l}\text { Non-Fatal Attacks } \\
\quad \text { Fatal Attacks }\end{array}$ & $46 \%$ & $16 \%$ \\
$\begin{array}{l}\text { Non-Serious Area } \\
\text { Number of Multiple Wound Attacks }\end{array}$ & $50 \%$ & $19 \%$ \\
$\begin{array}{l}\text { \% of- } \\
\quad \text { Non-Fatal Attacks }\end{array}$ & 29 & 5 \\
Fatal Attacks & $26 \%$ & $5 \%$ \\
\hline
\end{tabular}

1 Does not include shotgun attacks resulting in multiple, non-serious area wounds.

trend, however, may be usefully compared with police estimates of the gravity of the most serious wound sustained by the victim. Since the gravity of the wound may reflect a number of factors independent of the attacker's intention, the use of these police data should be secondary, to safeguard against any unwarranted inferences from the wound location data.

The police classify knife wounds as "slash" and "puncture" wounds. Slash wounds involve a shallower penetration than puncture wounds. Some gun wounds are classified by the police as "grazing," less serious wounds. The police estimates (see Table 9) indicate:

$34 \%$ of the serious area knife wounds were slash wounds; $25 \%$ involved only one serious area slash wound. If this latter group is excluded, $59 \%$ of the knife attacks resulted in puncture wounds to serious areas or multiple knife wounds.

$9 \%$ of the serious area firearm wounds were grazings. Excluding these leaves $56 \%$ of all firearm attacks resulting in serious area or multiple gunshot or shotgun wounds.

Excluding slash and graze wounds from attacks in earnest is not necessarily the best method of arriving at final figures. While slash and graze wounds where there was only one serious area wound may have resulted from less ominous attack intentions than penetrating wounds, the dangerousness of the area where the wound was sustained militates against this interpretation. Nevertheless, the exclusion results in a conservative estimate of the proportions of knife and gun attacks which are in earnest.

These statistics support two complementary propositions: (1) a roughly equal proportion of knife and gun attacks are of the kind which may not have been attacks in earnest, and (2) a roughly equal proportion of police reported knife and gun attacks are of the kind that suggest the 
TABLE 9

Police-Noted Extent of Wound by Weapon and ARea of Wound: Non-Fatad Attacks, Chicago, November 9-December 6, 1967

\begin{tabular}{|c|c|c|c|}
\hline \multicolumn{4}{|c|}{ Serious Area } \\
\hline \multicolumn{4}{|l|}{ Knife1 } \\
\hline Puncture & 66 & Wound & 92 \\
\hline \multirow[t]{2}{*}{ Slash } & 34 & Graze & 9 \\
\hline & $100 \%$ & & $100 \%$ \\
\hline Number of Cases & 247 & & 106 \\
\hline \multicolumn{4}{|c|}{ Non-Serious Area } \\
\hline Knife & & Gun & \\
\hline Puncture & 70 & Wound & 99 \\
\hline \multirow[t]{2}{*}{ Slash } & 30 & Graze & 1 \\
\hline & $100 \%$ & & $100 \%$ \\
\hline Number of Cases & 110 & & 81 \\
\hline
\end{tabular}

1 Does not include one "menaced."

2 Does not include 29 "missed."

attack was probably seriously intended. If the area of wounding is taken as an index of seriousness, a greater number of knife wounds than gun wounds are presumptively in earnest, and a lesser number of knife wounds than gun wounds are of the kind where the location of the attack creates some doubt about the earnestness of the attack. If the presence or absence of multiple shooting or stabbing is examined, nothing about the data suggests that the average knife attack is any less seriously intended than the average gun attack. Indeed, multiple knife attacks are more common per 100 reported attacks than multiple gun attacks. Finally, if all single knife slash wounds are removed from the class of presumptively serious attacks, this still leaves roughly equal proportions of presumptively serious attacks, with the gun figure slightly higher than the knife figure. If all single and multiple knife slash wounds are removed from the class of presumptively serious attacks, a rather radical use of the data, a gap of less than $10 \%$ opens between knife attacks considered presumptively serious and gun attacks considered presumptively serious.

The implications of these data on the basic question posed about weapon dangerousness can best be set into perspective by taking the most negative interpretation of the attack statistics and tracing its implications. If it is assumed that only those wounds inflicted by knives in serious area locations that resulted in police reported punctures can be presumptively considered attacks in earnest, but that every gunshot attack reported is an attack in earnest or worse, the death rate per 100 
attacks in earnest by guns would still be two and one-half times that of the death rate per 100 attacks in earnest by knives. Certainly, more reasonable use of these data would involve a substantially smaller number of asymmetrical assumptions. If the comparison is between knife puncture wounds in serious areas and gun wounds in serious areas, guns exhibit a death rate five times greater than knives.

Thus, when the data on the character of assaults are discussed in light of assault rates by weapon in Chicago and death rates by weapon in Chicago, a difference in attack intentions by weapon great enough to explain the differential death rates experienced is highly unlikely.

\section{CoNCLUSION}

The beginning of the present exercise is found in a crude but suggestive set of ratios: the rate of homicide per 100 police reported attacks is about five times as great for firearms as for knives, the next most dangerous weapon available in Chicago's homicide experience. Since a very substantial part of Chicago's homicide rate appears to be attributable to ambiguously motivated deadly attacks, it seems clear that the deadliness of a particular weapon in an attack situation is a significant determinant of the homicide rate. If this is true, then the killing per 100 attack ratio cited above is a conclusive demonstration that the absence of firearms would depress the otherwise expectable homicide rate, unless the disproportionate number of killings per police reported attack could be explained by a plausible rival hypothesis.

We have sought an explanation which would comport with the reality of homicide in Chicago and still explain the disproportionate killing per attack ratios noted in official statistics. The biases built into the way attacks are reported could only work to understate rather than overstate the disproportionate dangerousness of firearm attacks. The remaining rival hypothesis was then phrased in the form of the prediction that the vast majority of all police reported knife attacks were non-earnest in nature and all of the police reported gun attacks were of the kind that were likely to produce ambiguously motivated homicides or worse. In fact, an investigation of patterns of knife and gun wounding has suggested that a roughly equal proportion of both knife and gun attacks appear to be of a class likely to produce the ambiguously motivated homicide. The negative conclusion available from these data has already been stated: It is highly unlikely that the attack in earnest hypothesis which seeks to differentiate knife and gun attacks could, in the light of our study of wound location, completely explain the difference in kill ratios previously noted. But what of an affirmative conclusion? 
It might be thought that the five to one kill ratio relationship between knives and guns, when combined with the apparent similarity of attack in earnest ratios, could lead to a prediction that the absence of firearms in Chicago's population would reduce Chicago's homicide experience by four-fifths of the present gun-attributable total, or by some other finite amount. Unfortunately, this is not the case. First, while a substantial proportion of all homicides can be thought to be ambiguously motivated, we cannot make that assumption about all homicides, and we cannot conclusively isolate the proportion of homicide experience which is attributable to this kind of attack. Since the single-minded attack with intent to kill surely results in death more often per 100 attacks than an ambiguously motivated attack in earnest, we cannot confidently exclude the number of single-minded killings which constitute a part of reported homicides. However, there are some interesting data which might bear on the proportion of single-minded killings. The proportion of multiple woundings is only slightly higher in fatal gun attacks than in non-fatal, serious gun attacks. Further, multiple wound figures in homicides for all of 1967 account for only $30 \%$ of the gunshot killing totals. This would tend to limit the number of "kill at any cost" cases which might exaggerate the impression of frearm dangerousness in the attack statistics.

Second, it is not unlikely that the apparent similarity between knife and gun attack figures does conceal some disproportion between the attack in earnest ratios noted in knife versus gun attacks. The only unlikely conclusion is that weapon dangerousness does not affect the gross expectable homicide rate. The precise extent of that effect is a matter for conjecture. On their face, the data suggest that the effect of firearm elimination would itself be quite substantial. But that phrase is a hedge, and the method of this inquiry is non-experimental. The words "quite substantial" are as far as the data will take us.

A final note should be taken of the initial assumption of this enterprise: that a degree of continuity exists between homicide and non-fatal but serious assaults with deadly weapons. The similarities between serious attacks reported by police and homicides are compelling. Both events fall with disproportionate impact on the Negro community, and upon a disproportionately high number of male victims. Since relationship is a confirmed element of a great many such attacks, both phenomena can be attributed to a similarly skewed group of attackers. ${ }^{9}$ The attack data do not reveal substantial differences between fatal attacks using particular weapon forms and serious area, non-fatal attacks involving the same weapon. During the sample period:

9 See Wolfgang, supra note 2, table 22, at 379; Murder ANALYsis-1966, supra note 6. 
$46 \%$ of the non-fatal knife attacks resulting in wounds to serious areas, and $50 \%$ of the fatal knife attacks, involved multiple wounds.

$16 \%$ of the non-fatal serious area firearm attacks, and $19 \%$ of the fatal shootings, resulted in multiple wounds. (See Table 8.)

Perhaps these data are telling us it would be advisable to shift the focus of concentration from the species of homicide to the genus of deadly attack. The portion of the population subject to this threat is as skewed as the homicide statistics indicate, but the problem is larger. In the final years of this decade, a further study of this culture of violence is an obligation to its survivors. 